International Joumal of Biological Sciences
2009; 5(7):659-666

(C) Ivyspring International Publisher. All rights reserved

Research Paper

\title{
Karyology of eight species of bats (Mammalia: Chiroptera) from Hainan Is- land, China
}

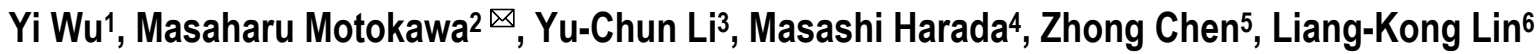

1. College of Life Science, Guangzhou University, Guangzhou 510006, China.

2. Kyoto University Museum, Kyoto 606-8501, Japan.

3. Marine College, Shandong University at Weihai, Weihai 264209, China.

4. Graduate School of Medicine, Osaka City University, Osaka 545-8585, Japan.

5. Department of Biology, Hainan Normal University, Haikou 571158, China.

6. Department of Life Science, Tunghai University, Taichung 407, Taiwan.

$\triangle$ Correspondence to: Masaharu Motokawa, Ph. D, Kyoto University Museum, Kyoto 606-8501, Japan. Phone +81-75-753-3287/FAX: +81-75-753-3276. E-mail: motokawa@inet.museum.kyoto-u.ac.jp.

Received: 2009.05.05; Accepted: 2009.10.16; Published: 2009.10.20

\begin{abstract}
Karyotypes and chromosomal data are presented for eight bat species representing two families (Rhinolophidae and Vespertilionidae) from Hainan Island, China. The species investigated were Rhinolophus lepidus $(2 \mathrm{n}=62, \mathrm{FN}=60), R$. pusillus $(2 \mathrm{n}=62, \mathrm{FN}=60), R$. affinis $(2 \mathrm{n}=62, \mathrm{FN}=60), R$. sinicus $(2 \mathrm{n}=36, \mathrm{FN}=60)$, Myotis horsfieldi $(2 \mathrm{n}=44, \mathrm{FN}=52)$, Pipistrellus abramus $(2 n=26, F N=44)$, Miniopterus australis $(2 n=46, F N=50)$ and $M$. schreibersii $(2 n=46, F N=50)$. The karyotype of Rhinolophus lepidus is reported for the first time.
\end{abstract}

Key words: Karyology; bats; Rhinolophidae; Vespertilionidae; chromosome; Hainan Island.

\section{Introduction}

Hainan Island is separated from the mainland of southern China by the narrow Strait of Hainan, which 17 to $20 \mathrm{~km}$ wide. It is the second largest island in China, with a land area of $34,000 \mathrm{~km}^{2}$, and the most southern province in China. The surface of Hainan Island is diversified geomorphologically, rising in the interior to mountains with altitudes exceeding 1,400 $\mathrm{m}$ near Wuzhishan and Jianfengling, which protect the southern part of the island from the monsoons. Hence, this region is quite different from the adjacent mainland of southern China climatically. The island's vegetation types include lowland shrubs, lowland evergreen forest, semi-evergreen forest, tropical rain forest, and montane evergreen forest. It has the best protected and largest area of primary tropical rain forest in China.

The fauna of Hainan Island comprises about 112 species of mammal, including 27 species of bat be- longing to seven families. In a survey of bats, three species were only recently recorded from Hainan Island [1-4]. Although all 27 bat species are considered to be conspecific with populations in southern China, subspecific status has been proposed for the Hainan populations of many taxa. Comparative studies of the populations in southern China and Hainan Island are needed to evaluate their degree of differentiation and to clarify their taxonomic status based on morphological and genetic perspectives. Conventional karyotyping is an important taxonomic tool for assessing the diversification between species, subspecies, and populations. Although 52 bat species in China have been karyotyped so far [5-17], no information is available for the bats of Hainan Island. This study reports the conventional karyotypes of eight species of bat representing two families (Rhinolophidae and Vespertilionidae) collected from Hainan Is- 
land as well as G- and C-banding karyotypes for selected species, and discusses their karyological relationships with conspecific populations and congeneric species in southern China and adjoining regions.

\section{Materials and Methods}

Twenty-eight specimens of eight species of bats were captured on Hainan Island, China in February 2005 and September 2008 (Table 1). The identification of these bats was based on standard taxonomic papers [18-21]. Voucher specimens are deposited in the College of Life Science, Guangzhou University, Guangzhou. Chromosome preparations were made from primary culture cells of lung and tail tissue using the methods of Harada and Yosida [22]. G- and C-banding differential stainings were applied for selected species following the methods of Seabright [23] and Sumner [24], respectively. The nomenclature of chromosomes follows Levan et al. [25]. The diploid number $(2 n)$ was determined by observing 30 metaphase cells in each specimen, and the fundamental number (FN) was defined as the total number of autosomal arms (Table 2).

Table I Species, numbers, and localities of bat specimens collected from Hainan Island, China examined in this study.

\begin{tabular}{|c|c|c|c|}
\hline Species & & $\mathrm{Fe}$ & Locality \\
\hline \multicolumn{4}{|l|}{ Rhinolophidae } \\
\hline Rhinolophus lepidus & 1 & 0 & Mt. Diao Luo (caves) \\
\hline \multirow[t]{2}{*}{ Rhinolophus pusillus } & 1 & 0 & Mt. Diao Luo (caves) \\
\hline & 4 & 2 & Qiongzhong, Caocan \\
\hline \multirow[t]{2}{*}{ Rhinolophus affinis } & 0 & 1 & Jianfengling, Tianchi \\
\hline & 4 & 1 & Qiongzhong, Caocan \\
\hline Rhinolophus sinicus & 2 & 1 & Mt. Diao Luo (caves) \\
\hline \multicolumn{4}{|l|}{ Vespertilionidae } \\
\hline Myotis horsfieldi & 1 & 0 & Wuzhishan, Diyicun \\
\hline Pipistrellus abramus & 1 & 7 & Jianfengling, Tianchi \\
\hline Miniopterus australis & 1 & 0 & Wuzhishan, Diyicun \\
\hline Miniopterus schreibersii & 1 & 0 & Mt. Diao Luo (caves) \\
\hline
\end{tabular}

Table 2 Karyotype data for the eight bat species collected from Hainan Island, China.

\begin{tabular}{|c|c|c|c|c|c|c|c|}
\hline \multirow[t]{2}{*}{ Species } & \multirow[t]{2}{*}{$2 n$} & \multirow[t]{2}{*}{ FN } & \multicolumn{3}{|c|}{ Autosome pair } & \multicolumn{2}{|c|}{ Sex chromosomes } \\
\hline & & & M-SM & ST & A & $X$ & $\mathrm{Y}$ \\
\hline Rhinolophus lepidus & 62 & 60 & 0 & 0 & 30 & ST & A \\
\hline $\begin{array}{l}\text { Rhinolophus pusil- } \\
\text { lus }\end{array}$ & 62 & 60 & 0 & 0 & 30 & ST & A \\
\hline Rhinolophus affinis & 62 & 60 & 0 & 0 & 30 & ST & A \\
\hline Rhinolophus sinicus & 36 & 60 & 13 & 0 & 4 & ST & ST \\
\hline Myotis horsfieldi & 44 & 50 & 4 & 0 & 17 & SM & A \\
\hline $\begin{array}{l}\text { Pipistrellus abra- } \\
\text { mus }\end{array}$ & 26 & 44 & 10 & 0 & 2 & A & A \\
\hline $\begin{array}{l}\text { Miniopterus aus- } \\
\text { tralis }\end{array}$ & 46 & 50 & 3 & 0 & 19 & SM & A \\
\hline $\begin{array}{l}\text { Miniopterus } \\
\text { schreibersii }\end{array}$ & 46 & 50 & 3 & 0 & 19 & SM & A \\
\hline
\end{tabular}

\section{Results and Discussion}

\section{Karyotypes of four species in the genus Rhinolo- phus}

This is the first karyotype description for Rhinolophus lepidus, which is widely distributed in Asia from Afghanistan to China, as well as in Sumatra [26]. The karyotype of R. lepidus from Hainan Island was $2 n=62$ and FN = 60 (Fig. 1), consisting of 30 medium-sized to small acrocentric autosomal pairs, a large subtelocentric $X$ chromosome, and a small acrocentric $Y$ chromosome. Secondary constrictions were detected adjacent to one pair of medium-sized acrocentric chromosomes.

The karyotypes of R. pusillus and R. affinis from Hainan Island were also $2 \mathrm{n}=62, \mathrm{FN}=60$ (Fig. 2A, B), consisting of 30 medium-sized to small acrocentric autosomal pairs, a large subtelocentric $X$ chromosome, and a small acrocentric $Y$ chromosome. A secondary constriction was detected in one pair of medium-sized acrocentric chromosomes in both species. Rhinolophus pusillus and R. affinis are widely distributed in the Indomalayan region and China and each contains nine subspecies [26]. The two subspecies from Hainan (R. pusillus parcus and R. affinis hainanus) examined in this study showed no karyological differences from previous reports for the following taxa: $R$. p. szechwanus from the Chinese provinces of Sichuan [14] and Guizhou [13] (reported as R. cornutus); R. p. calidus from the Chinese provinces of Anhui [6] (as R. cornutus pumilus) and Guangdong [15] (as R. cornutus); R. p. lakkhanae from Thailand [27]; R. a. himalayanus from the Chinese provinces of Guizhou [12] and Henan [28]; R. a. macrurus from the Chinese provinces of Anhui [6] and Guangdong [15] (as $R$. affinis); and R. a. macrurus from Thailand [27].

The reported comparative karyological data for 35 Rhinolophus species in the world [6, 15, 27-31] suggest that the karyotype $2 \mathrm{n}=62, \mathrm{FN}=60$ is likely the conserved among the species and subspecies of the genus Rhinolophus and is shared by R. lepidus, R. pusillus, R. affinis, R. macrotis, R. rex, and R. huananus (reported as $R$. macrotis [15]). Karyotype of $R$. lepidus is also considered a member of this $2 \mathrm{n}=62, \mathrm{FN}=60$ karyotype without recognized difference in G-banding pattern compared with Mao et al. [17]. This $2 \mathrm{n}=62, \mathrm{FN}=60$ karyotype was thought to be ancestral state of the genus Rhinolophus, but recent karyotype study suggested that $2 \mathrm{n}=58$ karyotype is more closely related to ancestral karyotype of the genus [17].

The karyotype of $R$. sinicus was $2 \mathrm{n}=36, \mathrm{FN}=60$ (Fig. 3), consisting of 13 large-to-small metacentric or submetacentric pairs and four medium-sized to small 
acrocentric pairs of autosomes, a medium-sized subtelocentric X chromosome, and a small subtelocentric $\mathrm{Y}$ chromosome. This species had a prominent secondary constriction involving one pair of medium-sized acrocentric chromosomes. The karyotype of $R$. sinicus from Hainan Island $(2 n=36, F N=60)$ does not differ from conspecific populations in the Chinese provinces of Anhui [6] (reported as R. rouxii sinicus), Sichuan [14], and Guangdong [15] in conventional karyotype and that from "south-western China" also in G-banding pattern [17], but does differ from the $2 n$ $=56, \mathrm{FN}=60$ karyotype of $R$. rouxii reported from India and Sri Lanka [31]. These karyological differences between $R$. sinicus and $R$. rouxii support the view that these two taxonomically confused taxa both represent distinct species, as previously proposed [14, $15,26]$.

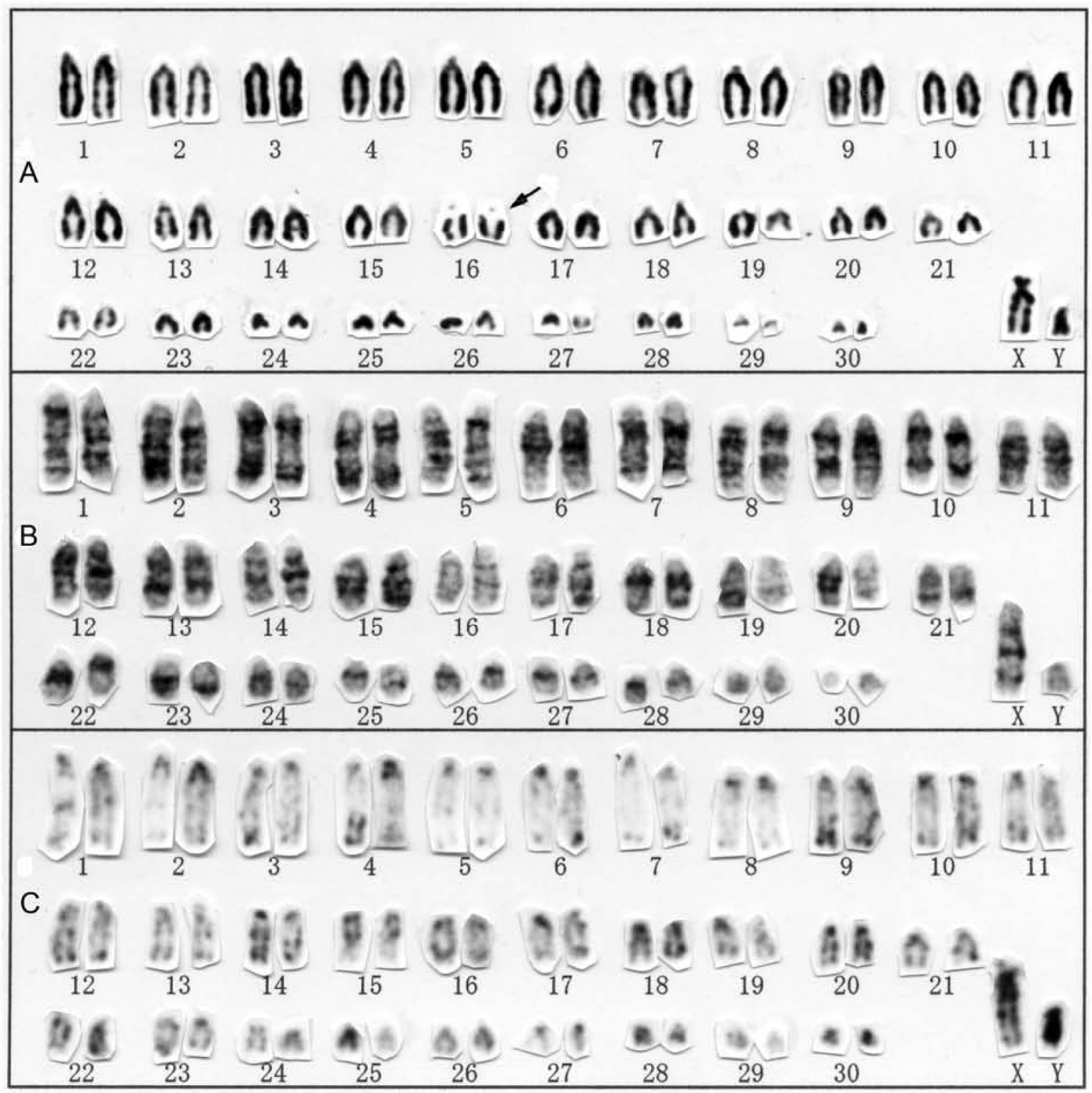

Figure I Conventional (A), G-banding (B), and C-banding karyotypes of Rhinolophus lepidus from Hainan Island, China. Secondary constrictions are indicated by arrows. 


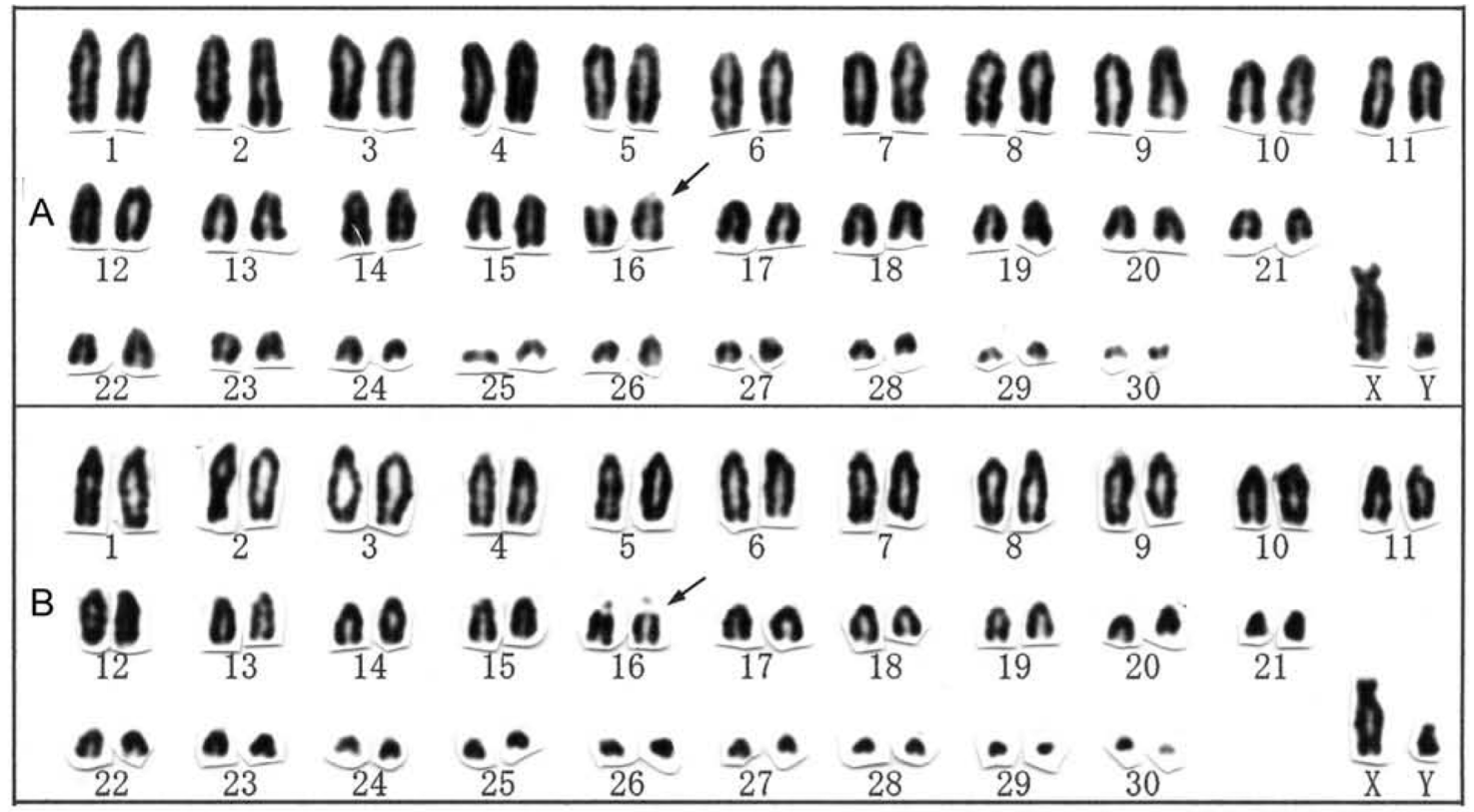

Figure 2 Conventional karyotypes of R. pusillus (A) and R. affinis (B) from Hainan Island, China. Secondary constrictions are indicated by arrows.

Figure 3 Conventional (A), G-banding (B), and C-banding karyotypes of Rhinolophus sinicus from Hainan Island, China. Secondary constrictions are indicated by arrows.

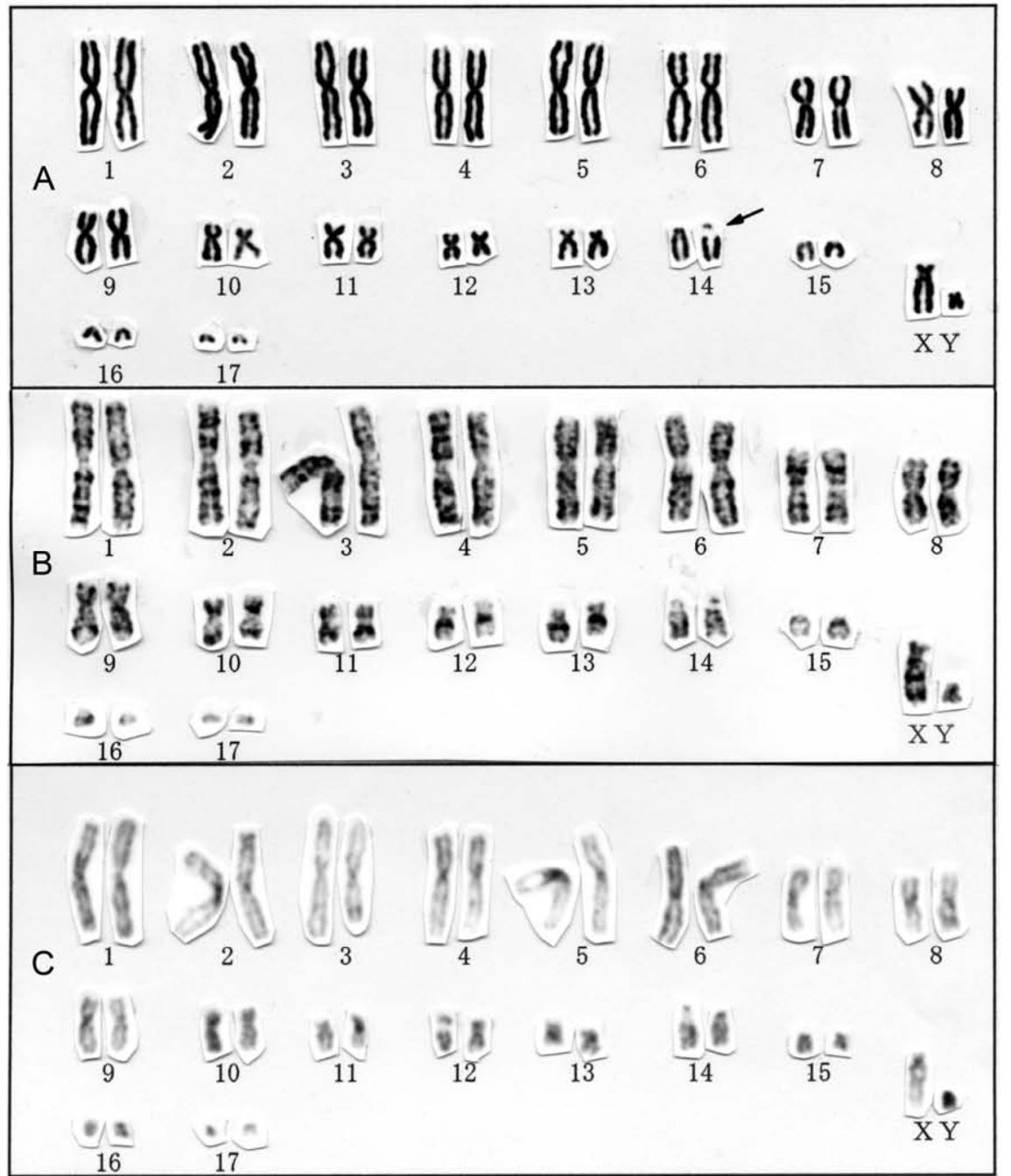




\section{The karyotype of Myotis horsfieldi}

The karyotype of Myotis horsfieldi was $2 \mathrm{n}=44$, $\mathrm{FN}=50$, consisting of three large and one small metacentric or submetacentric pairs and 17 medium-sized to small acrocentric pairs in autosomes, a medium-sized submetacentric $X$ chromosome, and a small acrocentric $\mathrm{Y}$ chromosome (Fig. 4A). The karyotype of Myotis horsfieldi from Hainan Island does not differ from conspecific population in Borneo [32]. The vespertilionid genus Myotis is one of the most diverse mammalian genera and includes 103 species [26], but it is also one of the most karyologically conservative genera. A diploid number $2 n=44$ characterizes all 47 species for which karyotypes have been reported [22, 33]. Chromosomal variation is essentially restricted to the presence of heterochromatic short arms on the smaller autosomes, variation in the location of active nucleolus organizer regions (NORs), as well as differences in the size of the $\mathrm{Y}$ chromosome [22, 33, 34]. In addition, an inverted autosome and a duplicated translocation involving the $\mathrm{X}$ chromosome have been reported in M. pruinosus [35]. An extra pair of acrocentric autosomes $(2 n=$ 46) has also been reported in $M$. annectans from Thailand [36] and in $M$. davidii from Guangdong [16]. The karyotype of $M$. horsfieldi in this study is the conservative one and showed no additional translocation.

Figure 4 Karyotypes of Myotis horsfieldi (A), Miniopterus australis (B), and $M$. schreibersii (C). Secondary constrictions are indicated by arrows.

\section{The karyotype of Pipistrellus abramus}

The karyotype of Pipistrellus abramus from Hainan Island was $2 n=26, F N=44$ (Fig. 5), consisting of ten large to medium-sized metacentric or submetacentric pairs and two small acrocentric pairs in autosomes, a medium-sized acrocentric $X$ chromosome, and the smallest acrocentric $\mathrm{Y}$ chromosome. The conventionally stained karyotype of $P$. abramus from Hainan Island does not differ from conspecific populations from the Chinese provinces of Zhejiang, Henan, and Sichuan, Taiwan, Japan, or Korea [8, 14, 37-43]. Large negative G-band and positive C-band areas were found in the pericentromeric regions of chromosome 1 through 4,10, 11 and X; and these are considered centromeric constitutive heterochromatin. This characteristic was also reported from Japan and Taiwan [38, 41, 42], and any difference in G- and C-banding patterns among populations from Hainan Island, Japan and Taiwan was detected.

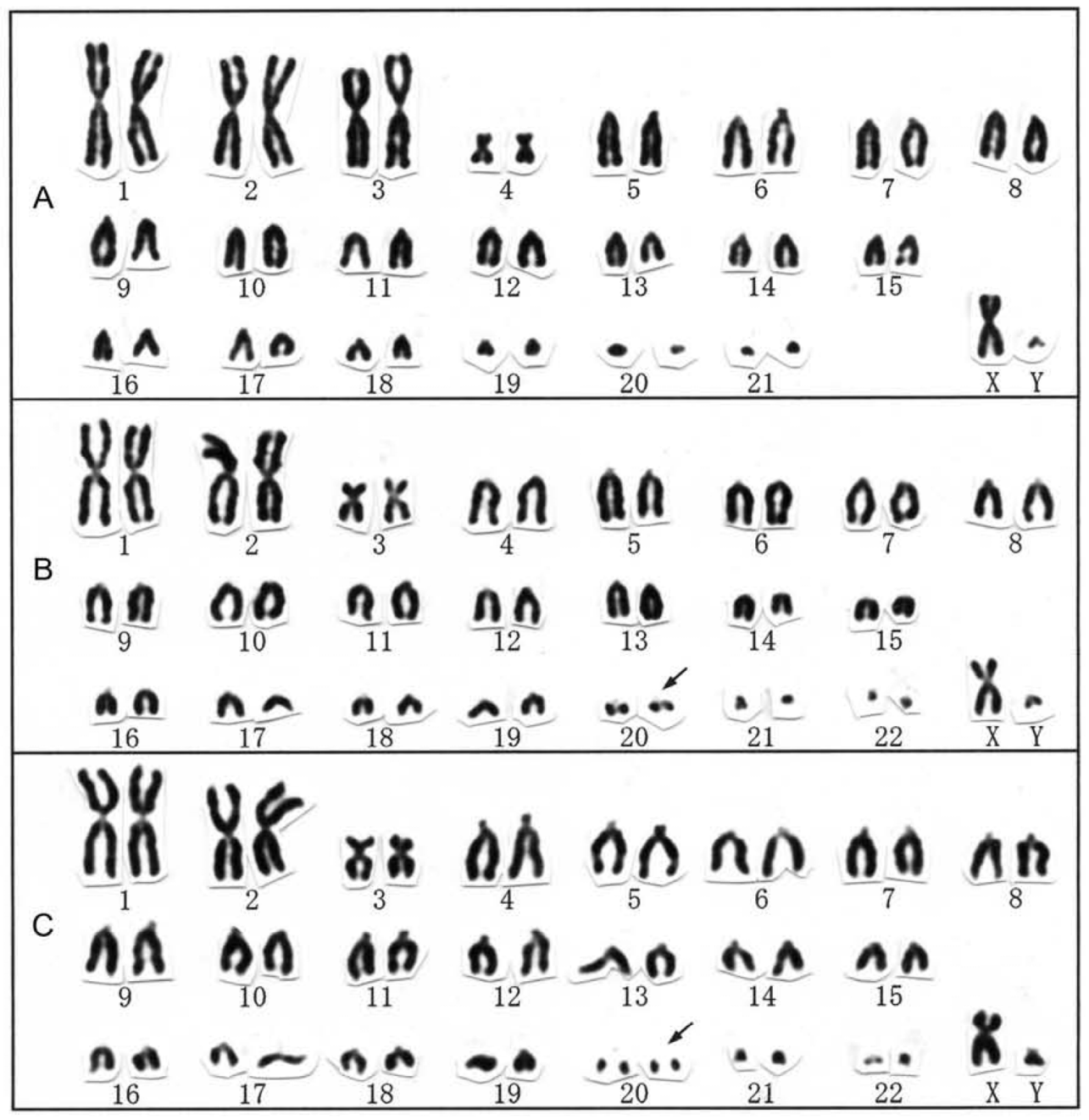




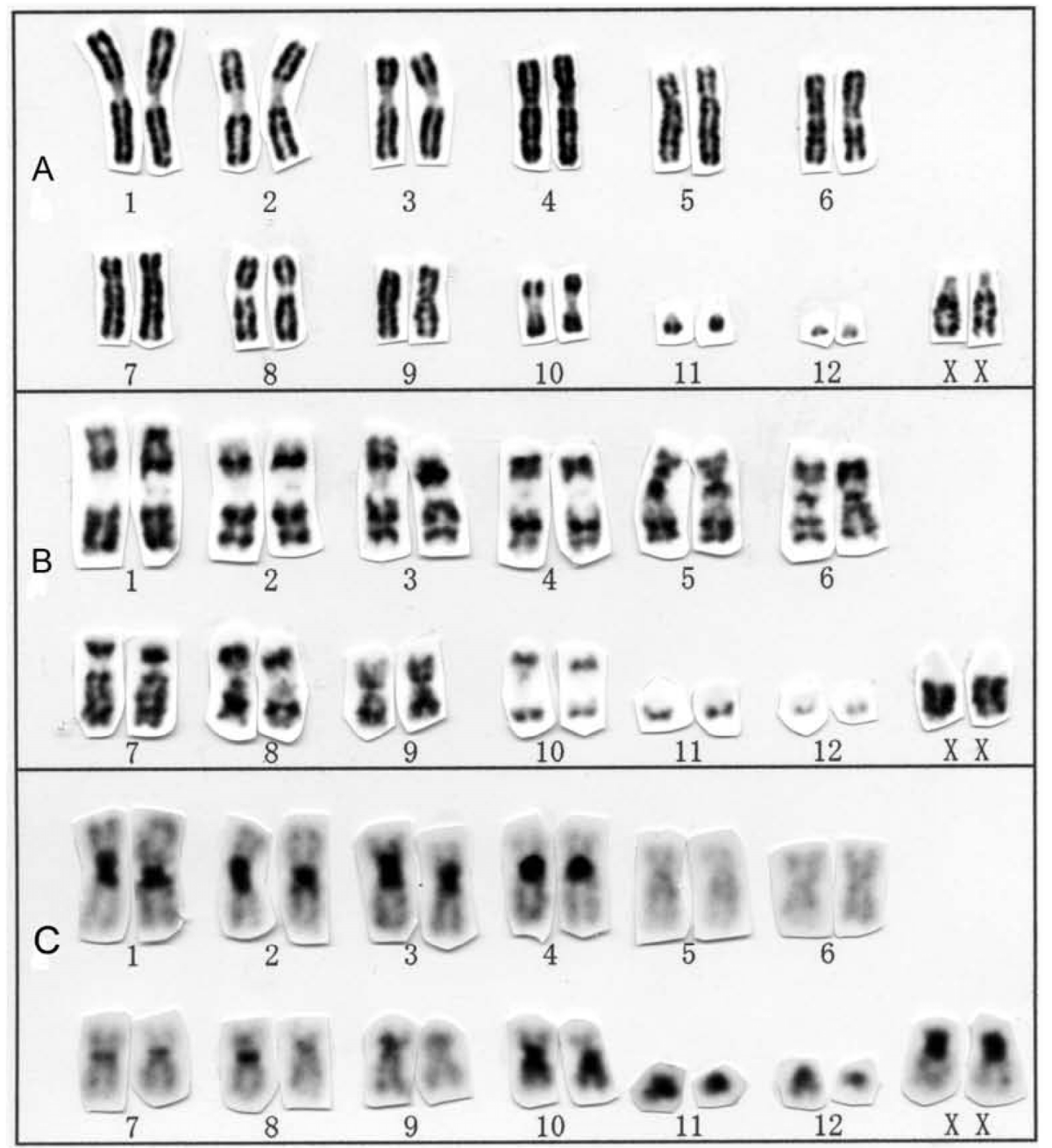

Figure 5 Conventional (A), G-banding (B), and C-banding karyotypes of Pipistrellus abramus from Hainan Island, China.

The karyotype of two species in the genus Miniopterus

The karyotypes of Miniopterus australis and $M$. schreibersii from Hainan Island were both $2 \mathrm{n}=46, \mathrm{FN}$ $=50$ (Fig. 4B, C), both consisting of two large and one small metacentric or submetacentric pairs and 19 medium-sized to small acrocentric pairs in autosomes, a submetacentric $\mathrm{X}$ chromosome, and an acrocentric $\mathrm{Y}$ chromosome. One small acrocentric pair (No. 20) had a secondary constriction adjacent to the centromere. The karyotype of M. australis from Hainan Island is very similar to a previous report for the same species from Borneo [32]. The karyotype of M. schreibersii from Hainan Island is similar to those for M. schreibersii from Borneo and Taiwan $[9,32]$, M. s. chinensis from Anhui Province, China [44], M. s. pallidus from Russia [45], and M. s. fuliginosus from Japan [40, 46] and Guizhou Province, China [47] (as M. fuliginosus). The members of this genus have likely retained the karyologically conservative state.

\section{Diversification of bats from Hainan Island}

Eight species of bats from Hainan Island examined in this study did not show any karyological differences from the conspecific populations or congeneric species from southern China and adjoining regions. Because karyological analyses suggest no evidences for differentiation, we follow the current taxonomic status to consider the Hainan bats as conspecific with the populations in southern China and adjoining regions. The karyological characteristics, however, are very conservative in some genera as discussed above. Morphological and genetic studies are also desired for more precise evaluation of the diversification and the taxonomic status of bats in Hainan Island.

\section{Acknowledgments}

We acknowledge grants from the National Natural Science Foundation of China (NSFC, No. 
30370167, 30499341, and 30670277) and the National Study Abroad Foundation of China (No. 21844046), and a NSFC-JSPS Joint Research Project Grant (No. 30811140092). We thank CD Wang, ZL Jiang, WH Yu, L Guo, and W Lei for their kind help with the field work on Hainan Island, China.

\section{Conflict of Interest}

The authors have declared that no conflict of interest exists.

\section{References}

1. Li YC, Wu Y, Chen Z. A new record of Rickett's big-footed bat Myotis ricketti in Hainan Island of China. Acta Theriologica Sinica 2006; 26(2): 211-212.

2. Zhang LB, Zhu GJ, Yu DM, Yu JP, Zhang W, Hong TY, Tan M. New record of Tylonycteris robustula (Chiroptera: Vespertilionidae) from Hainan, Guizhou, Sichuan Province. Acta Theriologica Sinica 2008; 28 (3): 316-320.

3. Yu WH, Wu Y, Li YC, Jiang HS, Chen Z. A new record of greater bamboo bat Tylonycteris robustula of Hainan Island. J Guangzhou Univ 2008; 7(5): 30-33.

4. Zhu GJ, Li DW, Yu JP, Hong TY, Zhang LB. New record of Ia io in Hainan island, its echolocation pulses and ND1 analysis. Chinese J Zool 2008; 43(5): 69-75.

5. Zhang WD. A study on karyotype of Myotis chinensis and M. laniger Peter. J Anhui Normal Univ 1984; 7: 42-47.

6. Zhang WD. A study on the karyotypes in four species of bat (Rhinolophus). Acta Theriologica Sinica 1985; 5: 95-101.

7. Zhang WD. Study on the karyotype of the Myotis. J Anhui Normal Univ 1989; 2: 71-77.

8. Yin LY, Xie X, Shi Y. Chromosomes of house bat Pipistrellus abramus Temminck. Acta Zool Sinica 1985; 31: 296-298.

9. Lin LK, Motokawa M, Harada M. Karyology of ten Vespertilionid bats (Chiroptera: Vespertilionidae) from Taiwan. Zool Stud 2002; 41: 347-354.

10. Zhang WD, Wang MO. Chromosomal analysis of Taphozous melanopogon and Hipposideros armiger. Acta Theriologica Sinica 1992; 12: 306-307.

11. Gu XM, Lu J, Han JL, Peng Y, Tu YY. A study on karyotype of two species of Pipistrellus. J Guizhou Normal Univ 2001; 19 (2): 12-14.

12. Gu XM, Tu YY, Jiang DC, Yang HJ, Wang Y. Karyotype analysis of five Rhinolophus species from Guizhou. Chinese J Zool 2003; 38 (1): 18-22.

13. Gu XM. The karyotypes of six species of bats from Guizhou. Chinese J Zool 2006; 41 (5): 112-116.

14. Wu Y, Harada M, Li YH. Karyology of seven species bats from Sichuan, China. Acta Theriologica Sinica 2004; 24: 30-35.

15. Wu Y, Harada M. Karyology of five species of the Rhinolophus (Chiroptera: Rhinolophidae) from Guangdong, China. Acta Theriologica Sinica 2005; 25:163-167.

16. Wu Y, Harada M, Shi HY, Liu H. Further study on karyology of bats (Mammalia: Chiroptera) from Sichuan, China. J Guangzhou Univ 2006; 5: 20-24.

17. Mao X, Nie W, Wang J, Su W, Ao L, Feng Q, Wang Y, Volleth M, Yang F. Karyotype evolution in Rhinolophus bats (Rhinolophidae, Chiroptera) illuminated by cross-species chromosome painting and G-banding comparison. Chromosome Res 2007; 15: 835-847.

18. Allen GM. The mammals of China and Mongolia. New York: American Museum of Natural History; 1938.

19. Corbet GB, Hill JE. The mammals of the Indomalayan region. Oxford: Oxford University Press; 1992.
20. Bates PJJ, DL Harrison. Bats of the Indian subcontinent. Sevenoaks: Harrison Zoological Museum; 1997.

21. Wang YX. A complete checklist of mammal species and subspecies in China. A taxonomic and geographic reference. Beijing: China Forestry Publishing House; 2003.

22. Harada M, Yosida TH. Karyological study of four Japanese Myotis bats (Chiroptera, Mammalia). Chromosoma 1978; 5: 283-291.

23. Seabright M. A rapid banding technique for human chromosomes. Lancet 1971; 2: 971-972.

24. Sumner AT. A simple technique for demonstrating centromeric heterochromatin. Exp Cell Res 1972; 75: 304-306.

25. Levan A, Fredga K, Sandberg A. Nomenclature for centromeric position on chromosomes. Hereditas 1964; 52: 201-220.

26. Simmons NB. Order Chiroptera. In: Wilson DE, Reeder DM, eds. Mammal Species of the World: A Taxonomic and Geographic Reference, 3rd ed. Baltimore: Johns Hopkins University Press; 2005: 312-529.

27. Harada M, Yenbutra S, Yosida TH. Cytogenetical study of Rhinolophus bats (Chiroptera, Mammalia) from Thailand. Proc Japan Acad 1985; 61: 455-458.

28. Yu Y, Niu H, Wang Y, Lu Q. Karyotype analysis of two Rhinolophus species from Henan. Sichuan J Zool 2006; 25: 739-742.

29. Ando K, Tagawa T, Uchida TA. Karyotypes of Taiwanese and Japanese bats belonging to the families Rhinolophidae and Hipposideridae. Cytologia 1980; 45: 423-432.

30. Ando K, Uchida TA. Karyotype analysis in Chiroptera. 11. Phylogenetic relationships in the genus Rhinolophus. Sci Bull Fac Agr Kyushu Univ 1974; 28: 119-129.

31. Zima J, Volleth J, Horacek I, Cerveny J, Cervena A, Prucha K, Macholan M. Comparative karyology of rhinolophid bats (Chiroptera: Rhinolophidae). In: Horacek I, Vorhali V, eds. Prague Studies in Mammalogy. Prague: Charles University Press; 1992: 229-236.

32. Harada M, Kobayashi T. Studies on the small mammal fauna of Sabah, East Malaysia II. Karyological analysis of some Sabahan Mammals (Primates, Rodentia, Chiroptera). Contr Biol Lab Kyoto Univ 1980; 26: 83-95.

33. Bickham JW. Chromosomal variation and evolutionary relationships of Vespertilionid bats. J Mamm 1979; 60: 350-363.

34. Volleth M. Differences in the location of nucleolus organizer regions in European vespertilionid bats. Cytogenet Cell Genet 1987; 44: 186-197.

35. Harada M, Uchida TA. Karyotypes of a rare species, Myotis pruinosus, involving pericentric inversion and duplicated translocation. Cytologia 1982; 47: 539-543.

36. Bickham JW, McBee K, Schlitter DA. Chromosomal variation among seven species of Myotis (Chiroptera: Vespertilionidae). J Mamm 1986; 67: 746-750.

37. Yu Y, Ma J, Niu H. Karyotypes of V. superans and P. abramus in Henan. Guizhou Agricultural Sciences 2006; 34 (6): 16-18.

38. Lin LK, Motokawa M, Harada M. Karyological study of the house bat Pipistrellus abramus (Mammalia: Chiroptera) from Taiwan with comments on its taxonomic status. Raffles Bull Zool 2002; 50: 507-510.

39. Takayama S. The chromosomes of a bat, Pipistrellus tralatitus abramus. Japan J Genet 1959; 34: 107-110.

40. Harada M. Chromosomes of nine chiropteran species in Japan (Chiroptera). La Kromosomo 1973; 91: 2885-2895.

41. Obara Y, Tomiyasu T, Saitoh K. Chromosome studies in the Japanese vespertilionid bats. II. G-banding pattern of Pipistrellus abramus. Proc Japan Acad 1976; 52: 383-386.

42. Obara Y, Tomiyasu T, Saitoh K. Chromosome studies in the Japanese vespertilionid bats. III. Preliminary observation of C-bands in the chromosomes of Pipistrellus abramus Temminck. Sci Rep Hirosaki Univ 1976; 23: 39-42. 
43. Yoo DH, Yoon MH. A karyotypic study on six Korean vespertilionid bats. Korean J Zool 1992; 35: 489-496.

44. Zhang WD, Wan M, LX Zhou. Chromosomal analysis of Miniopterus schreibersi chinensis. Acta Theriologica Sinica 1983; 5: 40-41.

45. Vorontsov NN, Radjabli SI, Volobuev VT. The comparative karyology of the vespertilionid bats, Vespertilionidae (Chiroptera). In Vorontsov NN, ed. The Mammals, 2nd edition. Moscow: All Union Mamm Conf Moscow; 1969: 16-21.

46. Tsuchiya K. Chromosomes of two insectivorous bat species from Japan (Chiroptera). J Mamm Soc Japan 1971; 5: 114-116.

47. Li N, Ao L, He SY, Gu XM. G-bands and C-bands in 3 species of Vespertilionidae. Chinese J Zool 2007; 42 (2): 96-101. 